\title{
Tissue-specific Accumulation of Flavonoids in Grape Berries is Related to Transcriptional Expression of $\mathrm{VvF}^{\prime} \mathrm{H}$ and $\mathrm{VvF3}{ }^{\prime} 5^{\prime} \mathrm{H}$
}

\author{
L. Mu, J.-J. He, Q.-H. Pan, F. He, C.-Q. Duan*
}

Centre for Viticulture and Oenology, College of Food Science and Nutritional Engineering, China Agricultural University, Beijing 100083, China

Submitted for publication: August 2013

Accepted for publication: November 2013

Key words: Flavonols, flavan-3-ols, anthocyanins, gene expression, teinturier cultivar Yan73

\begin{abstract}
The products and the related gene expression of flavonoid metabolism were examined in the skin and pulp of Yan73 (Vitis vinifera L. cv.) grapes, a teinturier variety cultivated in China, and the data were compared with those in the skin and pulp of Cabernet Sauvignon (Vitis vinifera L. cv.) grapes, a well-known red variety. The results showed that, in comparison with the skins of Cabernet Sauvignon, the skins of Yan73 berries were characterised by fewer types of flavonols and anthocyanins, a higher level of flavonoids, and a much lower percentage of $3^{\prime}$-hydroxylated flavonols. Flavonoid metabolism was also present in the pulp of Yan73, and the percentages of $3^{\prime}$-hydroxylated flavonols and 3 '-hydroxylated flavan-3-ols were significantly higher than the percentages of their corresponding $3^{\prime}, 5^{\prime}$-hydroxylated forms. Only flavan-3ols were found in the pulp of Cabernet Sauvignon. The expression of $V v m y b A 1$ exhibited a co-ordination with the accumulation of anthocyanins in the pulp of the teinturier cultivar, which showed great similarity to that in the skin. A good correlation was found between the expression of $V v F 3^{\prime} H$ and $3^{\prime}$-hydroxylated flavonoids, as well as between the expression of $V v F 3^{\prime} 5^{\prime} H$ and $3^{\prime}, 5^{\prime}$-hydroxylated flavonoids in the skin and pulp of the grape berries. It is suggested that tissue-specific accumulation of flavonoids in grape berries is related to the transcriptional expression of $V v F 3^{\prime} H$ and $V v F 3^{\prime} 5^{\prime} H$.
\end{abstract}

\section{INTRODUCTION}

Yan73 (Vitis vinifera L. cv.) is a teinturier variety cultivated in China. It was obtained in 1966 from the hybridisation of Alicante Bouschet (Vitis vinifera L. cv.) as female parent and Muscat Hamburg ( $V$. vinifera L. cv.) as male parent (Kong et al., 2004). Due to abundant accumulation of pigments in both the skin and the pulp, this grape cultivar is applied in winemaking to strengthen red wine colour. It was found that Yan73 wine also had higher phenolic content and stronger antioxidant capacity compared to the wine of a non-teinturier variety, namely Cabernet Sauvignon ( $V$. vinifera L. cv.) (Xi et al., 2013). Anthocyanin pigments redden the berry skins of grapevine cultivars as well as wines fermented in the presence of red skins. Since colour is critical to the sensory evaluation of red wine, due to its great commercial value, there have been a number of studies on anthocyanin biosynthesis and accumulation, as well as its regulation in wine grape berries (Boss et al., 1996; Kobayashi et al., 2002; Jeong et al., 2004; Ageorges et al., 2006; Jeong et al., 2006; Mattivi et al., 2006; Castellarin \& Di Gaspero, 2007; Castellarin et al., 2007; Matus et al., 2009).

In addition to anthocyanins, the contribution of flavonols and flavan-3-ols in grape fruits to the sensory quality of wine should not be ignored. Firstly, these two types of flavonoids are the main co-pigments participating in hue formation and colour stability during fermentation. Secondly, they are important components in determining the bitterness and astringency of wine. However, in terms of the teinturier grape varieties, most previous studies have focused only on the anthocyanin profiles (Ageorges et al., 2006; Balík \& Kumšta, 2008; Castillo-Muñoz et al., 2009; He et al., 2010; Falginella et al., 2012; Guan et al., 2012), a few reports were concerned about their flavonol profiles (Castillo-Muñoz et al., 2007; Castillo-Muñoz et al., 2009), while to date no report has dealt with flavan-3-ol profiles. Since these three kinds of flavonoids make a collaborative contribution to the quality of red wine, it is valuable to thoroughly understand the composition and content of flavonoids in both the skin and pulp of a teinturier variety, as this will help to predict the potential impact on the colour and mouth feel of red wine when this teinturier variety is considered in winemaking.

The biosynthesis of flavonols, flavan-3-ols and anthocyanins share the same upstream pathway, as shown in Fig. 1 (Kobayashi et al., 2002). Some flavonoids have a B-ring di-hydroxyl group at the $3^{\prime}$ and 4' positions, which are called $3^{\prime}$-hydroxylated flavonoids and include quercetin, dihydroquercetin, isorhamnetin and their derivatives; $(+)$-catechin, (-)-epicatechin and (-)-epicatechin-3-O-gallate; and cyanidin and peonidin monoglucosides and their acylated

*Corresponding author: E-mail address: chqduan@cau.edu.cn [Tel \& Fax: +86-10-6273-7136]

Aknowledgements: This work was financially supported by the National Natural Science Foundation of China (Grant No.: 30871746 to C.-Q. D) 
derivatives. Other flavonoids have a tri-hydroxylated B-ring with an additional hydroxyl group at the $5^{\prime}$ position, known as $3^{\prime}, 5^{\prime}$-hydroxylated flavonoids; examples are myricetin, dihydromyricetin, laricitrin, syringetin and their derivatives; (-)-epigallocatechin; and glycosylated forms of delphinidin, petunidin and malvidin and their acylated derivatives. The 3'-hydroxylated flavonoids are products of the downstream pathway of flavonoid 3'-hydroxylase (F3'H), whereas $3^{\prime}, 5^{\prime}$-hydroxylated flavonoids are from the downstream pathway of flavonoid $3^{\prime}, 5^{\prime}$-hydroxylase $\left(\mathrm{F}^{\prime}{ }^{\prime} 5^{\prime} \mathrm{H}\right)$. Naringenin flavanone is the common substrate shared by these two parallel pathways $\left(\mathrm{F}^{\prime} \mathrm{H}\right.$ and $\left.\mathrm{F}^{\prime} 5^{\prime} \mathrm{H}\right)$. Therefore, $\mathrm{F}^{\prime} \mathrm{H}$ and $\mathrm{F}^{\prime} 5^{\prime} \mathrm{H}$ are key enzymes that control the production of $3^{\prime}$-hydroxylated and 3',5'-hydroxylated flavonoids respectively (Winkel-Shirley, 2001). Meanwhile, the 3' position and the sequential $5^{\prime}$ position can be methoxylated by $O$-methyltransferase (OMT) to generate methoxylated flavonoids. The methylation of anthocyanin can modify its stability and reactivity, and influence the colour of grape berries and wine (Castellarin \& Di Gaspero, 2007).

Although the anthocyanin profile and expression of flavonoid-synthetic genes have been studied in teinturier grape berries (Ageorges et al., 2006; Balík \& Kumšta, 2008; Castillo-Muñoz et al., 2009; He et al., 2010; Obreque-Slier et al., 2010; Lago-Vanzela et al., 2011; Falginella et al.,
2012; Guan et al., 2012), these studies paid little attention to the tissue-specific accumulation of various flavonoids and their relationship with the expression of the biosynthesisrelated genes in the skin and pulp of teinturier grapes. Our previous study indicated that the pulp in Yan73, compared with the skin, contained a lower ratio of $3^{\prime}, 5^{\prime}$-hydroxylated to $3^{\prime}$-hydroxylated anthocyanins and a higher ratio of methoxylation to non-methoxylation of the anthocyanin B-ring (He et al., 2010). This showed that the distribution of assimilated carbon in various branch pathways of anthocyanin metabolism is completely different in the skins and the pulp. Although there are great differences in anthocyanin and flavonoid profiles between the skin and the pulp in Yan73, the present study still cannot define whether these differences are as a result of the tissue-specific expression of genes encoding key enzymes in their biosynthetic pathway, or of flavonoid transportation from skin to pulp. As far as we know, the tissue-specific accumulation of various flavonoids and the underlying genetic mechanism responsible for these differences have not yet been elucidated clearly in teinturier grape varieties.

The present study was performed to further explore the association between flavonoid composition and expression patterns of key enzyme genes for flavonoid biosynthesis in the skin and pulp of teinturier variety Yan73, as well as their

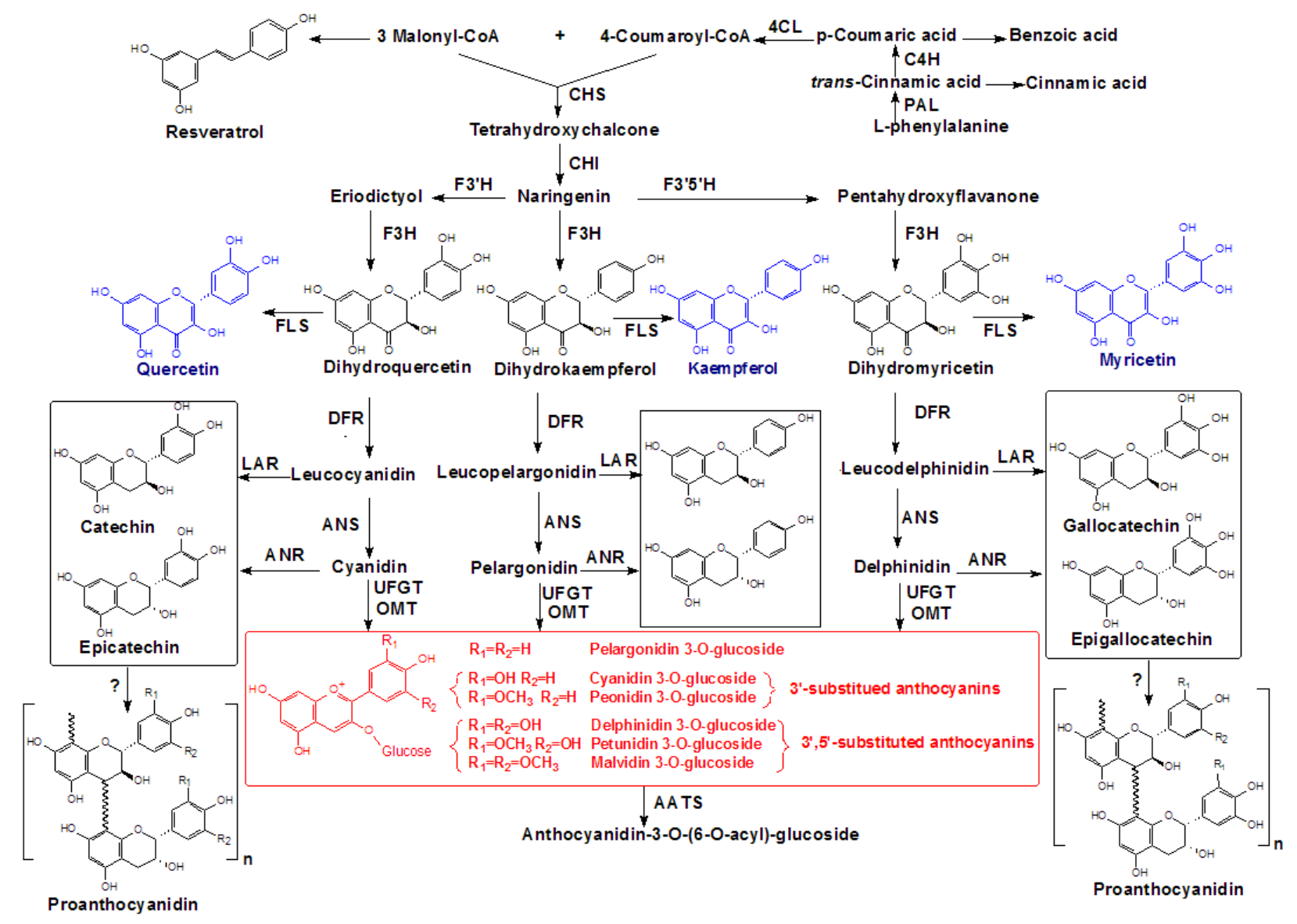

FIGURE 1

General biosynthetic pathways of flavonoids in grapes. CHS: chalcone synthase; CHI: chalcone isomerase; F3H: flavanone 3-hydroxylase; DFR: dihydroflavonol 4-reductase; ANS: leucoanthocyanidin deoxygenase; UFGT: UDP-glucose:flavonoid 3-O-glucosyltransferase; F3'H: flavanone 3'-hydroxylase; F3'5'H: flavanone 3',5'-dihydroxylase; OMT: $O$-methyltransferase; AATs: anthocyanin acyltransferases. 
comparison with those of the non-teinturier variety Cabernet Sauvignon. The objective of this study was to dissect the mechanism underlying the distinct accumulation of various flavonoid components in different tissues and different grape varieties. These findings will enrich the knowledge of the genetic regulation of flavonoid biosynthesis in the grape berry.

\section{MATERIALS AND METHODS \\ Plant material}

Yan73 and Cabernet Sauvignon grape berries have been growing for nearly 10 years in the commercial vineyards of Beijing, China. They were sampled from the beginning of véraison to industrial harvest (total soluble solids of approximately $20^{\circ}$ Brix to $22^{\circ}$ Brix) in 2010 . The dates when these two cultivars commenced véraison were different: Yan73 on 2010-07-21, and Cabernet Sauvignon on 201008-03. In this study, the sampling time point was defined as 0 week after véraison, when approximately $5 \%$ of the berries on a cluster had turned colour and approximately $10 \%$ of the berry on $50 \%$ of the clusters had softened. Yan 73 grape berries were harvested on 2010-09-20, and Cabernet Sauvignon on 2010-10-12.

Representative samples of the whole vineyard population were achieved according to the method reported by Boulton et al. (1995). On each sampling day, three 100-berry samples of each variety were collected from seven 10 -cluster selections at a similar position on at least 50 whole grapevines. The sampling time was fixed at 10:00 to 11:00. These berry samples were carried back to the laboratory within two hours. After being washed with distilled water, samples were immediately separated by hand to skins, pulps and seeds . Each sample was frozen in liquid nitrogen, and part of it was ground to fine powder with the help of liquid nitrogen and then lyophilised for the flavonoid analysis; the rest was stored at $-80^{\circ} \mathrm{C}$ for the gene expression analysis.

\section{Flavonoid extraction}

Anthocyanin extraction was performed with methods reported by He et al. (2010). In brief, skin powder or pulp powder $(1.0 \mathrm{~g})$ was homogenised in methanol solution $(20 \mathrm{~mL})$ containing 1\% formic acid. Anthocyanin extraction was performed with the aid of ultrasonic treatment for $10 \mathrm{~min}$. The solution was incubated in the dark at $25^{\circ} \mathrm{C}$ for $30 \mathrm{~min}$, followed by a centrifugation at $8000 \times g$ for $20 \mathrm{~min}$, and the supernatant was collected. The extraction step was repeated four times by adding another $20 \mathrm{~mL}$ of methanol solution to the pellet each time. All supernatants were pooled in a distilling flask and processed through a rotary evaporator to remove the methanol solution. The residues were dissolved into $10 \mathrm{~mL} 12 \%$ ethyl alcohol solutions ( $\mathrm{pH} 3.7$, adjusted by acetic acid) and used for the analysis of the anthocyanins.

Flavonol extraction from the skin or the pulp was performed according to the previous method, with some modification (Jin et al., 2010). Skin or pulp powder weighing $2.00 \mathrm{~g}$ was mixed with distilled water $(5 \mathrm{~mL})$ and ethyl acetate $(45 \mathrm{~mL})$, then incubated with gentle shaking in darkness for $30 \mathrm{~min}$, followed by centrifugation. The residue was extracted repeatedly for five times. All the supernatants were collected, dried using a rotary evaporator, and then re- dissolved with chromatographic-grade methanol $(2 \mathrm{~mL})$ for the analysis of the flavonols.

The sum of flavan-3-ol monomers and polymers was determined after acid catalysis in the presence of excess phloroglucinol (Liang et al., 2012). The catalytic solution was composed of $50 \mathrm{~g} / \mathrm{L}$ phloroglucinol in methanol, $5 \mathrm{~g} / \mathrm{L}$ ascorbic acid and $0.1 \mathrm{M} \mathrm{HCl}$. Powder $(0.1 \mathrm{~g})$ was added to this solution $(1 \mathrm{~mL})$, which was then incubated at $50^{\circ} \mathrm{C}$ for $20 \mathrm{~min}$. Aqueous sodium acetate $(200 \mathrm{mM})$ of $1 \mathrm{~mL}$ was used to stop the reaction. After centrifugation, the residue was extracted repeatedly for five times, as reported before, after which all the supernatants were pooled and used for the analysis of flavan-3-ols.

Three independent replicates of the extractions were conducted for each skin sample or pulp sample.

\section{Qualitative and quantitative analyses of flavonoids by HPLC-MS}

The anthocyanin solution was filtered through a $0.45 \mu \mathrm{m}$ filter (cellulose acetate and nitrocellulose, CAN) and used for qualitative and quantitative analyses with the help of highperformance liquid chromatography-mass spectrometry (HPLC-MS) (Han et al., 2008). An Agilent 1100 series LCMSD trap VL, equipped with a DAD detector and reversed phase column (Kromasil C18, $250 \times 4.6 \mathrm{~mm}, 5 \mu \mathrm{m}$ ), was used. The mobile phase was: (A) aqueous $2 \%$ formic acid, and (B) acetonitrile containing $2 \%$ formic acid. The gradient elution was from $6 \%$ to $10 \% \mathrm{~B}$ for $4 \mathrm{~min}$, from $10 \%$ to $25 \%$ B for $8 \mathrm{~min}$, isocratic $25 \%$ B for $1 \mathrm{~min}$, from $25 \%$ to $40 \%$ for $7 \mathrm{~min}$, from $40 \%$ to $60 \%$ for $15 \mathrm{~min}$, from $60 \%$ to $100 \%$ for $5 \mathrm{~min}$, from $100 \%$ to $6 \%$ for $5 \mathrm{~min}$, at a flow rate of $1.0 \mathrm{~mL} / \mathrm{min}$. The injection volume was $30 \mu \mathrm{L}$, and the detection wavelength was $525 \mathrm{~nm}$. MS conditions were as follows: electrospray ionisation (ESI) interface, positive ion model, 35 psi nebuliser pressure, $10 \mathrm{~L} / \mathrm{min}$ dry gas flow rate, $350^{\circ} \mathrm{C}$ dry gas temperature, and scans at $\mathrm{m} / \mathrm{z} 100$ to 1000 . The identification of five basic non-acylated anthocyanins was confirmed by comparison with commercially available anthocyanin standards and the MS/MS spectra. Identification of all the other acylated anthocyanins was achieved mainly by comparing molecular ions and product ions of these anthocyanins with those available in the literature (GarcíaBeneytez et al., 2002, 2003; Wang et al., 2003; Núñez et al., 2004; De Villiers et al., 2004; Downey \& Rochfort, 2008; Han et al., 2008; Cook Papini et al., 2010). The cis and trans isomers of the coumaroylates for peonidin-3-Oglucoside and malvidin-3-O-glucoside were distinguished by elution time and proportion. The $c i s$ isomers were eluted first on a reverse-phase HPLC column, and presented lower proportions than trans isomers in the grapes according to the data reported previously (García-Beneytez et al., 2003; Núñez et al., 2004; Downey \& Rochfort, 2008). The concentration of individual anthocyanins was represented as micrograms of malvidin-3-O-glucoside equivalent per gram dry weight of tissues (DW).

Qualitative analysis of the flavonols was performed through an Agilent 1100 series LC-MSD trap VL, equipped with a DAD detector and reversed phase column (Zorbax SB-C18 column $3 \mathrm{~mm} \times 50 \mathrm{~mm}, 1.8 \mu \mathrm{m}$ ), as previously reported by us (Jin et al., 2010). Flavonol extraction was 
filtered through $0.22 \mu \mathrm{m}$ nylon membrane filters prior to analysis. The mobile phase was composed of (A) aqueous $1 \%$ acetic acid and (B) acetonitrile containing $1 \%$ acetic acid. The gradient elution processing was from $5 \%$ to $8 \% \mathrm{~B}$ for $10 \mathrm{~min}$, from $8 \%$ to $10 \% \mathrm{~B}$ for $8 \mathrm{~min}$, from $10 \%$ to $15 \%$ for $22 \mathrm{~min}$, from $15 \%$ to $20 \%$ for $10 \mathrm{~min}$, from $20 \%$ to $30 \%$ for $3 \mathrm{~min}$, from $30 \%$ to $50 \%$ for $5 \mathrm{~min}$, from $50 \%$ to $100 \%$ for $4 \mathrm{~min}$, and isocratic $100 \% \mathrm{~B}$ for $4 \mathrm{~min}$, at a flow rate of $1.0 \mathrm{~mL} / \mathrm{min}$. Injection volumes were $2 \mu \mathrm{L}$ and the detection wavelength was $280 \mathrm{~nm}$. MS conditions were as follows: electrospray ionisation (ESI) interface, negative ion mode, 35 psi nebuliser pressure, $10 \mathrm{~mL} / \mathrm{min}$ dry gas flow rate, $325^{\circ} \mathrm{C}$ dry gas temperature, and scans at m/z 100 to 1000 . The identification of flavonols was confirmed by comparison with commercially available flavonol standards and the MS/ MS spectra. The concentration of flavonols was represented as microgram quercetin equivalent per gram dry weight of tissues (DW).

Flavan-3-ols extracts were filtered through $0.22 \mu \mathrm{m}$ nylon membrane filters and then separated by an Agilent 1100 series LC-MSD trap VL, equipped with a DAD detector and reversed phase column (Lorbax SB-C18 column $4.6 \mathrm{~mm}$ $\times 250 \mathrm{~mm}, 5 \mu \mathrm{m})$ (Liang et al., 2012). The mobile phase was composed of (A) aqueous $0.2 \%$ acetic acid and (B) acetonitrile and aqueous $0.2 \%$ acetic acid mixed at $4: 1$. The gradient was isocratic $10 \%$ B for $20 \mathrm{~min}$, from $10 \%$ to $15 \%$ B for $10 \mathrm{~min}$, from $15 \%$ to $20 \%$ B for $10 \mathrm{~min}$, from $20 \%$ to $33 \%$ for $10 \mathrm{~min}$, from $33 \%$ to $40 \%$ B for $5 \mathrm{~min}$, from $40 \%$ to $100 \%$ B for $3 \mathrm{~min}$, isocratic $100 \%$ B for $5 \mathrm{~min}$, from $100 \%$ to $10 \% \mathrm{~B}$ for $1 \mathrm{~min}$, at a flow rate of $1.0 \mathrm{~mL} / \mathrm{min}$. Injection volumes were $25 \mu \mathrm{L}$, and the detection wavelength was 280 $\mathrm{nm}$. MS conditions were as follows: electrospray ionisation (ESI) interface, negative ion mode, 35 psi nebuliser pressure, $10 \mathrm{~mL} / \mathrm{min}$ dry gas flow rate, $325^{\circ} \mathrm{C}$ dry gas temperature, and scans at $m / z 100$ to 1000 . Identification of the flavan-3-ols was confirmed by comparison with available standards and MS/MS spectra. The flavan-3-ol monomers and the acidcleavaged extension subunits, as well as the phloroglucinol adducts of the acid-cleavaged terminal flavan-3-ol subunits, were identified by their standards $(+)$-catechin, (-)-epicatechin, (-)-epigallocatechin and (-)-epicatechin3-O-gallate respectively, and by their corresponding MS information in the negative ion mode. The concentration of flavan-3-ol monomers was quantified by the standard curves prepared from the commercial standards.

\section{Real-time PCR}

Total RNA of the skin or the pulp of the grape berries was extracted using a cetyltriethylammnonium bromide (CTAB) extraction buffer (He et al., 2009). All RNA samples were incubated with DNase I (RNase free, Takara, Japan) and purified by the EZ-10 Spin Column RNA Purification Kit (BioBasic, Canada). The quality of RNA was verified by checking intact ribosomal bands through agarose gel electrophoresis and the absorbance ratios (A260/A280). All the purified RNA samples were adjusted to the same concentration of $50 \mathrm{ng} / \mu \mathrm{L}$ with RNase-free water, and reverse transcribed into cDNA using AMV reverse transcriptase (Takara, Japan) according to the manufacturer's instructions. The quantification of the transcripts was performed using SYBR ${ }^{\circledR}$ Premix Ex Taq ${ }^{\mathrm{TM}}$ (Takara, Japan) on a 7300 Real-Time PCR System (Applied Biosystems, USA). Each real-time PCR reaction $(20 \mu \mathrm{L})$ contained $2.0 \mu \mathrm{L}$ of the cDNA template $(100 \mathrm{ng} / \mu \mathrm{L}), 1.6 \mu \mathrm{L}$ of the primer mixture (10 $\mu \mathrm{M}$ each, mixed with equivalent volume), $10.0 \mu \mathrm{L}$ of $2 \times$ SYBR Premix Ex Taq II and $0.4 \mu \mathrm{L}$ of $50 \times$ ROX Reference Dye (Takara, Japan), and $6.0 \mu \mathrm{L}$ of $\mathrm{dH}_{2} \mathrm{O}$. The template cDNA was denatured at $95^{\circ} \mathrm{C}$ for $30 \mathrm{sec}$, followed by 40 cycles of amplification at $95^{\circ} \mathrm{C}$ for $10 \mathrm{sec}, 60^{\circ} \mathrm{C}$ for $31 \mathrm{sec}$ and a melt cycle from $60^{\circ} \mathrm{C}$ to $95^{\circ} \mathrm{C}$. Key enzyme genes and $V v$ Ubiquitin were analysed simultaneously. Two replicates were performed with each grape sample to get two pieces of RNA, then reverse transcribed into cDNA, and three technical replicates of Real-Time PCR were conducted on each cDNA sample.

The primers for real-time PCR were as referred to in previous reports (Jeong et al., 2004; Bogs et al., 2005, 2006; Castellarin et al., 2007). These sequences are shown in Table 1. The efficiency of these primers was tested in preliminary experiments with templates of dilutions of the purified PCR product, and maintained a $\gamma^{2}$ value $\geq 0.98$. VvUbiquitin cDNA was used as an internal control. The specificity of the primers was verified on the basis of the following experiments. Firstly, using cDNA from grape berries as a template, specific fragments were obtained through PCR amplification. Fragment sizes were $182 \mathrm{bp}$ for $V v$ Ubiquitin, 69 bp for $V v F 3 H 1,129$ bp for $V v F 3 H 2,150$ bp for $V v D F R, 338 \mathrm{bp}$ for $V v A N S, 152 \mathrm{bp}$ for $V v U F G T$, $171 \mathrm{bp}$ for $V v F 3^{\prime} H, 101 \mathrm{bp}$ for $V v F 3^{\prime} 5^{\prime} H, 159 \mathrm{bp}$ for $V v O M T$ and 369 bp for $V v m y b A 1$,. These fragments were sequenced from both the 3 '-end and 5 '-end respectively, and compared with nucleotide sequences published in Genbank. The results demonstrated that they were exactly the same. Secondly, the dissociation curve of each gene indicated an absence of primer, dimer or other non-specific products. The dissociation curve was obtained at $95^{\circ} \mathrm{C}$ for $15 \mathrm{sec}$ and $60^{\circ} \mathrm{C}$ for $1 \mathrm{~min}$.

The relative transcript abundance for each gene was quantified by normalising to the expression level of $V v U b i q u i t i n$. Every run, for each sample, included the VvUbiquitin control. The $2^{-\Delta \mathrm{Ct}}\left(\Delta \mathrm{Ct}=\mathrm{Ct}_{\mathrm{Target}}-\mathrm{Ct}_{\text {Ubiquitin }}, \mathrm{Ct}\right.$ : cycle threshold) was used to obtain the normalised expression level of the target genes (Bogs et al., 2005).

\section{RESULTS}

\section{Changes of flavonoid contents in the skin and the pulp}

In this study, 13 flavonols, four flavan-3-ol monomers and their acid-cleavaged adducts, as well as 21 anthocyanins, were identified in the skin and pulp of ripening Yan73 and Cabernet Sauvignon berries. The flavonoids identified in the skin and the pulp of Yan73 and Cabernet Sauvignon at harvest are shown in Table 2. Four flavan-3-ols, viz. (-)-epigallocatechin (EGC), (+)-catechin (C), (-)-epicatechin (EC), and (-)-epicatechin-3-O-gallate (ECG), were present in both the skin and the pulp of Yan73. Fewer types of flavonols and anthocyanins were present in the skin of the Yan73 berries in comparison with the Cabernet Sauvignon berries. Similar development trends between the skin and the pulp of Yan73 were observed as to total concentration of each type of flavonoid (Fig. 2). Their total concentration 
TABLE 1

Specific primers for real-time PCR.

\begin{tabular}{|c|c|c|}
\hline Gene name & GenBank accession number & Sequences of primers ( $5^{\prime}$ to $\left.3^{\prime}\right)$ : forward/reverse \\
\hline VvUbiquitin & BN000705 & $\begin{array}{l}\text { F: 5'-GTGGTATTATTGAGCCATCCTT-3' } \\
\text { R: 5'-AACCTCCAATCCAGTCATCTAC-3' }\end{array}$ \\
\hline$V v F 3 H 1$ & X75965 & $\begin{array}{l}\text { F: 5'-CCAATCATAGCAGACTGTCC-3' } \\
\text { R: 5'-TCAGAGGATACACGGTTGCC-3' }\end{array}$ \\
\hline$V v F 3 H 2$ & AM430949 & $\begin{array}{l}\text { F: 5'-CTGTGGTGAACTCCGACTGC-3' } \\
\text { R: 5'-CAAATGTTATGGGCTCCTCC-3' }\end{array}$ \\
\hline$V v D F R$ & X75964 & $\begin{array}{l}\text { F: 5'-GGCTTTCTAGCGAGAGCGTA-3' } \\
\text { R: 5'-ACTCTCATTTCCGGCACATT-3' }\end{array}$ \\
\hline$V v A N S$ & X75966 & $\begin{array}{l}\text { F: 5'-ACCTTCATCCTCCACAACAT-3' } \\
\text { R: 5'-AGTAGAGCCTCCTGGGTCTT-3' }\end{array}$ \\
\hline$V v U F G T$ & AF000372 & $\begin{array}{l}\text { F: 5'-GGGATGGTAATGGCTGTGG-3' } \\
\text { R: 5'-ACATGGGTGGAGAGTGAGTT-3' }\end{array}$ \\
\hline$V v F 3^{\prime} H$ & AJ880357 & $\begin{array}{l}\text { F: 5'-CCAAGTTTTCGGGAAGTAAATG-3' } \\
\text { R: 5'-TACCCCTTGAGAATCATCGTTT-3' }\end{array}$ \\
\hline$V v F 3^{\prime} 5^{\prime} H$ & AJ880356 & $\begin{array}{l}\text { F: 5'-GCATGGATGCAGTTAAGTAGAAAA-3 } \\
\text { R:5'-ATATGGCTTGGTGGTAGAATGAAACGA-3' }\end{array}$ \\
\hline$V v O M T$ & BQ796057 & $\begin{array}{l}\text { F: 5'-GAGAGCAGGCAGAGTCCATC-3' } \\
\text { R: 5'-CACCATAAGCAAACCCTAAACC-3' }\end{array}$ \\
\hline VvmybAl & AB097923 & $\begin{array}{l}\text { F: 5'-TAGTCACCACTTCAAAAAGG-3' } \\
\text { R: 5'-GAATGTGTTTGGGGTTTATC-3' }\end{array}$ \\
\hline
\end{tabular}
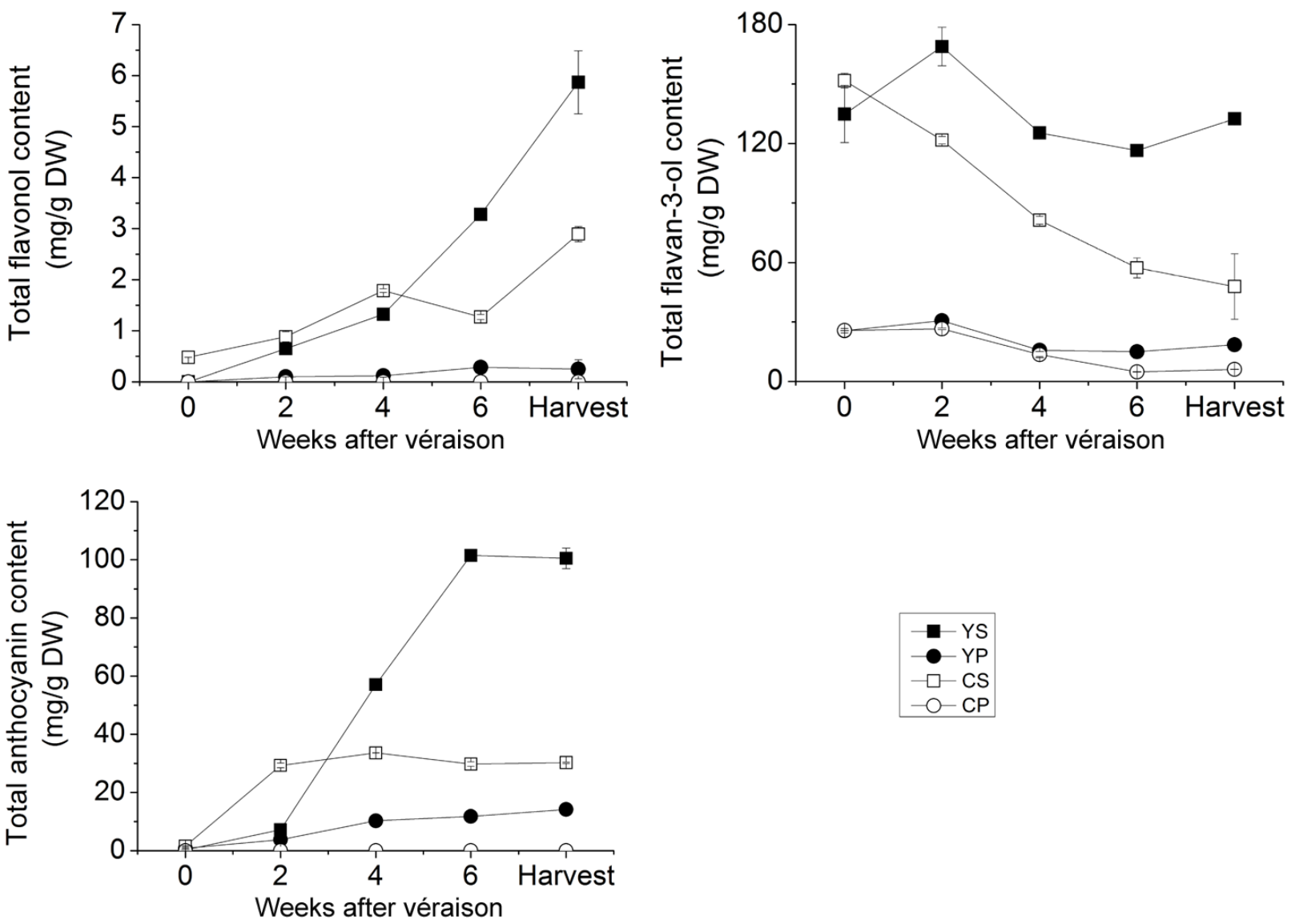

FIGURE 2

Total content of flavonols, flavan-3-ols and anthocyanins in the skin and pulp of Yan73 and Cabernet Sauvignon respectively. No flavonoid compounds were detected in the pulp of Cabernet Sauvignon. In the present experiment, detection limits of the flavonol compounds, flavan-3-ols and anthocyanins were $0.05 \mathrm{mg} / \mathrm{L}, 0.075 \mathrm{mg} / \mathrm{L}$ and $0.13 \mathrm{mg} / \mathrm{L}$ respectively. YS: the skin of Yan73; YP: the pulp of Yan73; CS: the skin of Cabernet Sauvignon; CP: the pulp of Cabernet Sauvignon; DW: dry weight of tissues. 
TABLE 2

Flavonoids identified in the skin and pulp of Yan73 and Cabernet Sauvignon at harvest (mg/g DW).

\begin{tabular}{|c|c|c|c|c|}
\hline Flavonoids & YS & YP & $\mathrm{CS}$ & $\mathrm{CP}$ \\
\hline \multicolumn{5}{|l|}{ Flavonols } \\
\hline Quercetin-3-O-glucoside & $0.29 \pm 0.08$ & trace & $0.34 \pm 0.002$ & nd \\
\hline Dihydroquercetin-3-O-glucoside & $0.08 \pm 0.01$ & nd & nd & nd \\
\hline Isorhamnetin-3-O-glucoside & nd & $0.07 \pm 0.001$ & $0.89 \pm 0.07$ & nd \\
\hline Myricetin-3-O-glucoside & $0.57 \pm 0.04$ & trace & $0.23 \pm 0.02$ & nd \\
\hline Laricitrin-3-O-glucoside & $0.31 \pm 0.03$ & nd & $0.07 \pm 0.009$ & nd \\
\hline Syringetin-3-O-glucoside & $0.05 \pm 0.001$ & nd & $0.09 \pm 0.0007$ & nd \\
\hline Quercetin-3-O-galactoside & trace & $0.02 \pm 0.0003$ & $0.09 \pm 0.004$ & nd \\
\hline Myricetin-3-O-galactoside & $3.79 \pm 0.45$ & $0.07 \pm 0.0001$ & $0.26 \pm 0.02$ & nd \\
\hline Laricitrin-3-O-galactoside & nd & trace & trace & nd \\
\hline Dihydroquercetin-3-O-rhamnoside & $0.47 \pm 0.03$ & trace & $0.07 \pm 0.009$ & nd \\
\hline Quercetin-3-O-glucuronide & trace & trace & $0.15 \pm 0.02$ & nd \\
\hline Quercetin-3-O-rutinoside & nd & nd & trace & nd \\
\hline Kaempferol-3-O-hexoside & trace & nd & $0.57 \pm 0.09$ & nd \\
\hline \multicolumn{5}{|l|}{ Flavan-3-ols } \\
\hline (-)-Epigallocatechin adduct & $28.87 \pm 0.26$ & $1.26 \pm 0.02$ & $14.86 \pm 0.94$ & $1.13 \pm 0.04$ \\
\hline (-)-Epigallocatechin & $10.29 \pm 0.24$ & $4.30 \pm 0.21$ & $4.26 \pm 0.005$ & $1.05 \pm 0.33$ \\
\hline$(+)$-Catechin adduct & $6.90 \pm 0.06$ & $0.35 \pm 0.008$ & $2.43 \pm 0.001$ & $0.26 \pm 0.0004$ \\
\hline (-)-Epicatechin adduct & $13.16 \pm 0.30$ & $1.23 \pm 0.02$ & $10.74 \pm 0.15$ & $1.58 \pm 0.23$ \\
\hline$(+)$-Catechin & $5.32 \pm 0.04$ & $0.08 \pm 0.0001$ & $0.32 \pm 0.008$ & $0.04 \pm 0.009$ \\
\hline (-)-Epicatechin-3-O-gallate adduct & $36.30 \pm 0.73$ & $8.25 \pm 0.23$ & $13.34 \pm 0.004$ & $1.09 \pm 0.009$ \\
\hline (-)-Epicatechin & $29.80 \pm 1.16$ & $1.82 \pm 0.08$ & trace & $0.009 \pm 0.0002$ \\
\hline (-)-Epicatechin-3-O-gallate & $1.78 \pm 0.04$ & $1.25 \pm 0.04$ & $1.90 \pm 0.01$ & $0.97 \pm 0.06$ \\
\hline \multicolumn{5}{|l|}{ Anthocyanins } \\
\hline Dephinidin-3-O-glucoside & $13.52 \pm 0.59$ & $0.43 \pm 0.03$ & $3.32 \pm 0.04$ & nd \\
\hline Cyanidin-3-O-glucoside & $2.25 \pm 0.036$ & $0.42 \pm 0.0003$ & $0.51 \pm 0.005$ & nd \\
\hline Petunidin-3-O-glucoside & $10.31 \pm 0.37$ & $0.58 \pm 0.01$ & $1.94 \pm 0.02$ & nd \\
\hline Pelargonidin-3-O-glucoside & $0.063 \pm 0.0008$ & $0.06 \pm 0.0004$ & $0.02 \pm 0.001$ & nd \\
\hline Peonidin-3-O-glucoside & $8.78 \pm 0.18$ & $5.53 \pm 0.01$ & $1.66 \pm 0.02$ & nd \\
\hline Malvidin-3-O-glucoside & $35.09 \pm 1.05$ & $4.01 \pm 0.004$ & $11.25 \pm 0.17$ & nd \\
\hline Dephinidin-3-O-(6-O-acetyl)-glucoside & $3.80 \pm 0.10$ & $0.18 \pm 0.003$ & $0.87 \pm 0.02$ & nd \\
\hline Cyanidin-3-O-(6-O-acetyl)-glucoside & $0.62 \pm 0.02$ & $0.07 \pm 0.01$ & $0.22 \pm 0.008$ & nd \\
\hline Petunidin-3-O-(6-O-acetyl)-glucoside & $3.40 \pm 0.13$ & $0.17 \pm 0.004$ & $0.73 \pm 0.004$ & nd \\
\hline Dephinidin-3-O-(6-O-coumaryl)-glucoside & $0.93 \pm 0.04$ & nd & $0.11 \pm 0.004$ & nd \\
\hline Peonidin-3-O-(6-O-acetyl)-glucoside & $2.16 \pm 0.09$ & $0.84 \pm 0.04$ & $0.67 \pm 0.03$ & nd \\
\hline Malvidin-3-O-(6-O-acetyl)-glucoside & $11.33 \pm 0.41$ & $1.10 \pm 0.02$ & $6.40 \pm 0.06$ & nd \\
\hline Peonidin-3-O-(6-O-caffeoyl)-glucoside & nd & nd & trace & nd \\
\hline Cyanidin-3-O-(6-O-coumaryl)-glucoside & $0.27 \pm 0.03$ & $0.04 \pm 0.005$ & $0.06 \pm 0.003$ & nd \\
\hline Malvidin-3-O-(6-O-caffeoyl)-glucoside & $0.04 \pm 0.006$ & $0.02 \pm 0.0003$ & $0.04 \pm 0.002$ & nd \\
\hline Petunidin-3-O-(6-O-coumaryl)-glucoside & $1.03 \pm 0.10$ & $0.05 \pm 0.005$ & $0.03 \pm 0.003$ & nd \\
\hline Peonidin-3-O-(cis-6-O-coumaryl)-glucoside & $0.05 \pm 0.006$ & nd & $0.04 \pm 0.005$ & nd \\
\hline Malvidin-3-O-(cis-6-O-coumaryl)-glucoside & $0.16 \pm 0.002$ & trace & $0.11 \pm 0.01$ & nd \\
\hline Peonidin-3-O-(trans-6-O-coumaryl)-glucoside & $1.01 \pm 0.06$ & $0.32 \pm 0.09$ & $0.28 \pm 0.01$ & nd \\
\hline Malvidin-3-O-(trans-6-O-coumaryl)-glucoside & $5.57 \pm 0.31$ & $0.35 \pm 0.05$ & $1.84 \pm 0.03$ & nd \\
\hline Malvidin-3-O-(6-O-feurlyl)-glucoside & $0.04 \pm 0.0003$ & nd & trace & nd \\
\hline
\end{tabular}

YS, YP, CS, and CP represent the skins of Yan73, the pulp of Yan73, the skins of Cabernet Sauvignon and the pulp of Cabernet Sauvignon respectively. DW means dry weight of tissues. Nd means not detected. Trace means a weak signal of the targeted compound was detected in MS, but the concentration of the compound could not be calculated from the peak area of the spectrum since it was too small. In the present study, the detection limit of malvidin-3-O-glucoside in methanol was $0.13 \mathrm{mg} / \mathrm{L}$; (+)-catechin, $0.075 \mathrm{mg} / \mathrm{L}$; quercetin, $0.05 \mathrm{mg} / \mathrm{L}$. 
in the skins was always much higher than that in the pulp. Comparing various types of flavonoids in the skins of these two varieties, we noticed that the total concentration of flavonols increased quickly from véraison to harvest in the skins of Yan73, while in the skins of Cabernet Sauvignon there was a steady increase; flavan-3-ols exhibited a first increase followed by a decrease in Yan73, but a continuous decline in the skins of Cabernet Sauvignon; there was a large accumulation of anthocyanins at the post-véraison stage in Yan73, but the accumulation of anthocyanins in Cabernet Sauvignon lagged far behind. Overall, the total concentration of each type of flavonoid in the skins of Yan73 was significantly higher than that in the skins of Cabernet Sauvignon, especially at harvest (Fig. 2). Flavonoids, i.e. flavonols, flavan-3-ols and anthocyanins, were all detected in the pulp of Yan73, while only flavan-3-ols were found in the pulp of Cabernet Sauvignon. The anthocyanins detected in the Cabernet Sauvignon pulp could be due to the migration of the pigments from the skin during the manual separation of the grape berry into its parts. The concentration of flavonols in Yan73 pulp changed a little during ripening, while its anthocyanins increased continuously. The concentration of flavan-3-ols detected in the pulps of Yan73 and Cabernet Sauvignon showed similar trends from véraison to harvest decreasing a bit, but then remaining the same.

According to the metabolic branch pathway, each type of flavonoid detected in this study was grouped into the corresponding 3'-hydroxylated and 3',5'-hydroxylated components, which are synthesised by the $\mathrm{F}^{\prime} \mathrm{H}-\mathrm{H}$ and F3'5'H-mediated pathways respectively (Fig. 3A, Fig. 3B).

\section{A}
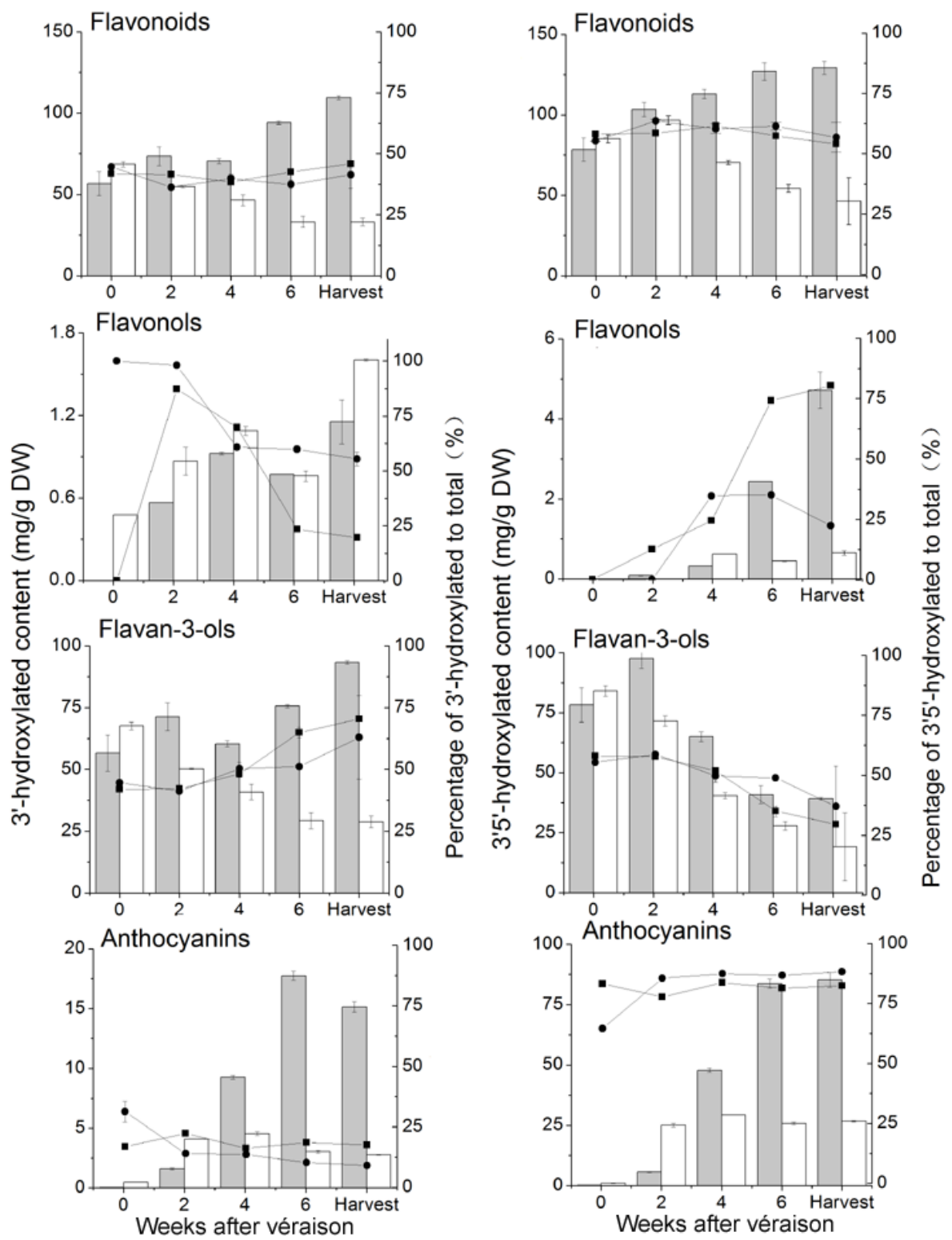

FIGURE 3A

Contents of various types of 3'-hydroxylated and 3',5'-hydroxylated flavonoids (vertical bar chart) and the percentage of the 3'-hydroxylated or 3',5'-hydroxylated form to total content of the corresponding type (line and scatter plot) in the skin of Yan 73 and Cabernet Sauvignon, and in the pulp of Yan73 and Cabernet Sauvignon respectively. YS: the skin of Yan73; YP: the pulp of Yan73; CS: the skin of Cabernet Sauvignon; CP: the pulp of Cabernet Sauvignon. 
From when the grapes just started changing colour until commercial harvest, the content of $3^{\prime}, 5^{\prime}$-hydroxylated flavonoids was always higher than that of $3^{\prime}$-hydroxylated flavonoids in both the Yan73 and the Cabernet Sauvignon skins. As for different grape varieties, the content of either 3'-hydroxylated or $3^{\prime}, 5^{\prime}$-hydroxylated flavonoids in this teinturier variety was always higher than that in Cabernet Sauvignon; the only exception seen was a lower level of flavonoids in the skins of Yan73 at the beginning of changing colour. This difference in the content between varieties was enhanced with fruit ripening. The total sum of flavonoids exhibited a gradual increase in the Yan 73 skins, but a decline in the Cabernet Sauvignon skins. Furthermore, regarding the percentage of 3'-hydroxylated and 3',5'-hydroxylated flavonoids to total flavonoids, no significant difference was observed between the skins of these two varieties, and these percentages remained at a relatively constant level during the whole experimental period, with an average of $42 \%$ and $58 \%$ in the Yan 73 skins and $41 \%$ and $59 \%$ in the Cabernet Sauvignon skins respectively (Fig. 3A). The percentage of 3'-hydroxylated flavonols in the Yan73 skins at harvest was about half that in the Cabernet Sauvignon skins, but the ratios of 3'-hydroxylated flavan-3-ols to 3'-hydroxylated anthocyanins were approximately three times those in the Cabernet Sauvignon skins (Fig. 3A). In contrast, the percentage of $3^{\prime}, 5^{\prime}$-hydroxylated flavonols in the Yan73 skins was significantly lower than that in the Cabernet Sauvignon skins, but this great difference in the percentage of flavonols between the two varieties did not produce any impact on the similar percentage of total 3'-hydroxylated

\section{B}
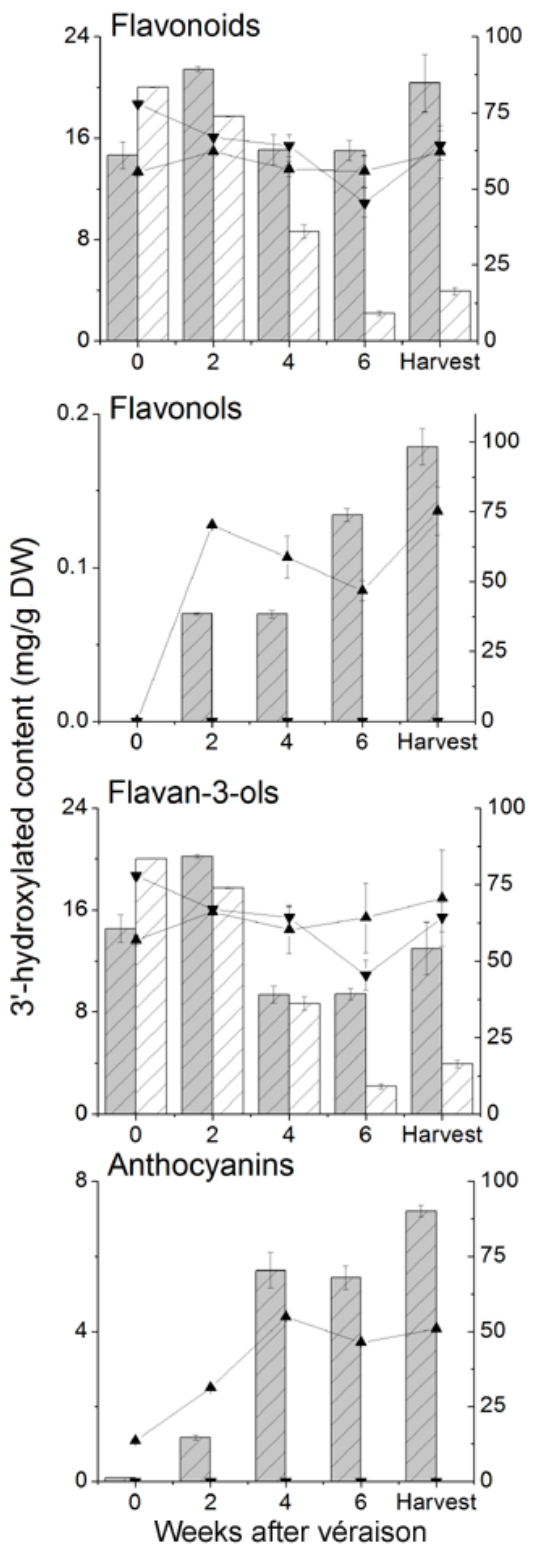
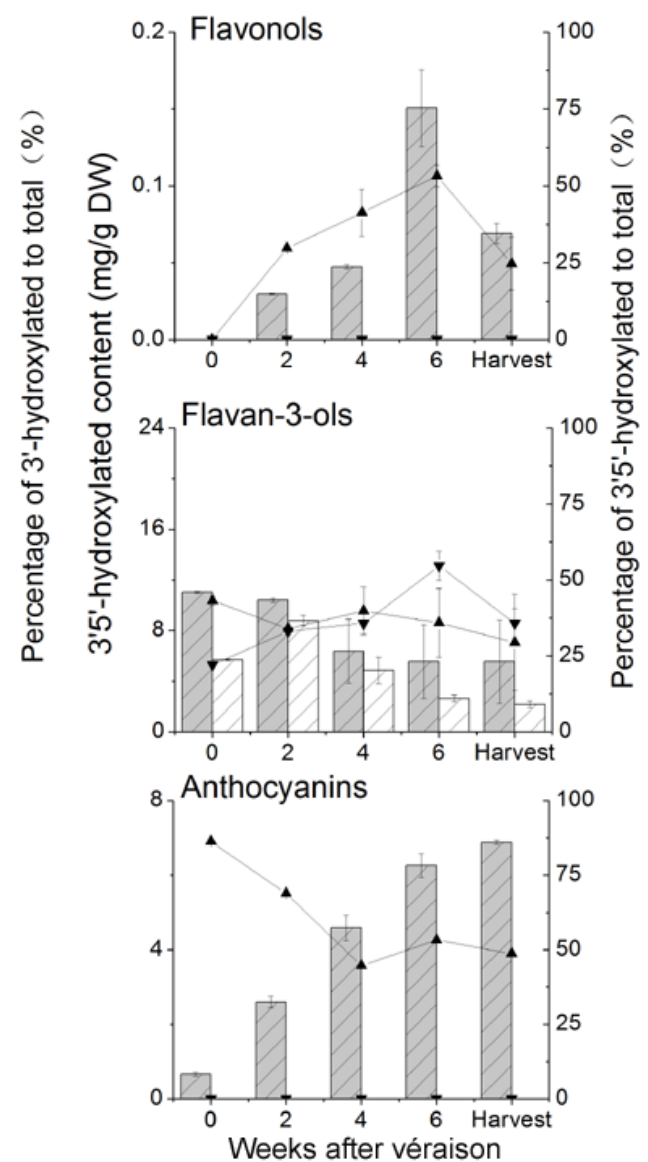

FIGURE 3B

Contents of various types of $3^{\prime}$-hydroxylated and $3^{\prime}, 5^{\prime}$-hydroxylated flavonoids (vertical bar chart) and the percentage of the $3^{\prime}$-hydroxylated or $3^{\prime}, 5^{\prime}$-hydroxylated form to total content of the corresponding type (line and scatter plot) in the skin of Yan73 and Cabernet Sauvignon, and in the pulp of Yan73 and Cabernet Sauvignon respectively. YS: the skin of Yan73; YP: the pulp of Yan73; CS: the skin of Cabernet Sauvignon; CP: the pulp of Cabernet Sauvignon. 
or $3^{\prime}, 5^{\prime}$-hydroxylated flavonoids mentioned above, because flavonols did not comprise a large amount in the sum of flavonoids. Apart from 3'-hydroxylated flavonols like quercetin derivatives, all other classes of flavonoids showed comparatively higher levels in Yan73 skins (Fig. 3A).

In contrast to the flavonoid composition in the skins, the percentage of 3',5'-hydroxylated flavonoids to total flavonoids in the Yan73 pulp stayed at a lower level, corresponding to approximately $41 \%$, compared with the percentage of 3'-hydroxylated flavonoids (Fig. 3B). This was mainly due to lower percentages of $3^{\prime}, 5^{\prime}$-hydroxylated flavan-3-ols. During the experimental periods, both $3^{\prime}$-hydroxylated and $3^{\prime}, 5^{\prime}$-hydroxylated flavonoids in the pulp of Yan73 did not show a significant change in total content, which differed from the developmental pattern of these compounds in the skin of Yan73. However, only flavan-3-ols were detected in the pulp of Cabernet Sauvignon, so their content could represent the flavonoid level (Fig. 3B). Compared with the flavan-3-ols in the Yan73 pulp, the content of the 3'-hydroxylated and 3',5'-hydroxylated flavan-3-ols was lower in the Cabernet Sauvignon pulp during grape develop, especially at harvest, and both of these flavan-3-ols decreased dramatically at the end of véraison, except for the 3'-hydroxylated flavan3 -ols, which decreased at the very beginning of véraison. In addition to 3 '-hydroxylated flavonols, such as quercetin derivatives, and $3^{\prime}, 5^{\prime}$-hydroxylated flavonols like myricetin derivatives, kaempherol-3-O-glucoside is a special type of flavonol in grape berries, and both the 3 '- and 5'- positions on the B-ring of this compound are not hydroxylated by a hydroxyl group or a methoxyl group. In the Yan73 skins, kaempherol-3-O-glucoside was detected only at four weeks and six weeks after véraison, and no kaempherol-3-Oglucoside was found in the pulp of Yan73 (Fig. 4).

Flavonoids also can be divided into two groups methoxylated and non-methoxylated flavonoids - according to whether methoxylation takes place on the flavonoid
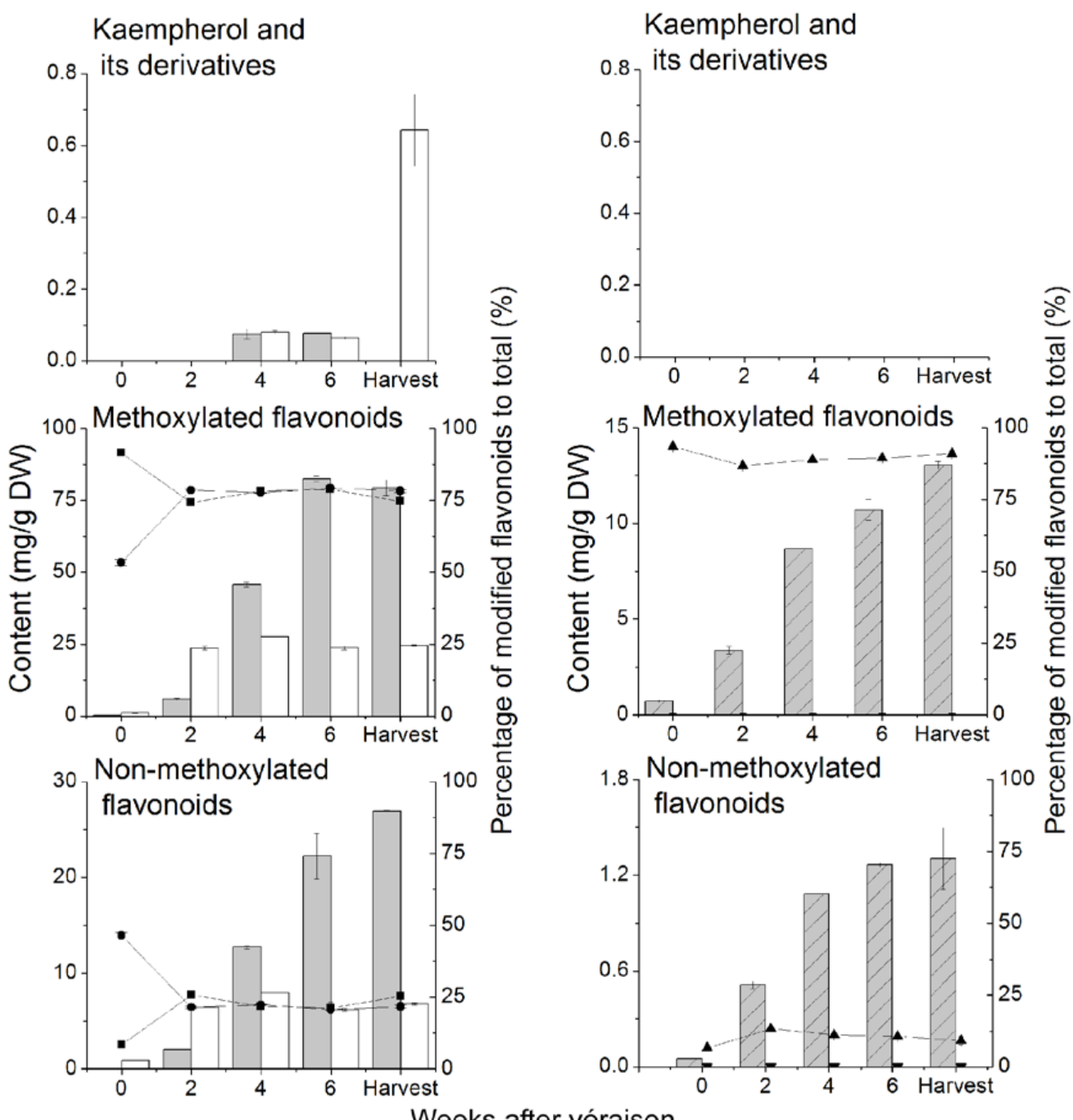

Weeks after véraison

\section{FIGURE 4}

Contents of kaempherol, methoxylated and non-methoxylated flavonoids (vertical bar chart) and their percentages (line and scatter plot) in the skin and pulp of Yan73 and Cabernet Sauvignon respectively. YS: the skin of Yan73; YP: the pulp of Yan73;

CS: the skin of Cabernet Sauvignon; CP: the pulp of Cabernet Sauvignon. 
B-ring or not. Methoxylated anthocyanins include peonidin3-O-glucoside, petunidin-3-O-glucoside and malvidin-3-Oglucoside and their acylated forms. Methoxylated flavonols are composed of the glycosidic derivatives of laricitrin, syringetin and isorhamnetin, while flavan-3-ols do not have methoxylated forms. In this study, the methoxylated forms of the flavonoids were over one-fold more than the nonmethoxylated forms in all the detected tissues. Moreover, both the methoxylated and non-methoxylated forms in the Yan73 skins gradually increased in content, and they remained to a certain degree in the Cabernet Sauvignon skins from two weeks after véraison (Fig. 4). The methoxylated flavonoids were composed mainly of the methoxylated form of anthocyanins, rather than that of flavan-3-ols and flavonols. The percentage of methoxylated anthocyanins in the pulp of Yan73 was much higher than that in the skins (data not shown).

\section{Expression of flavonoid biosynthesis-related genes and VvmybA1 in the skins and pulp}

To understand the relationship between the tissue-specific distribution of flavonoids and the expression of the related genes, we detected the relative expression of $V v F 3^{\prime} H$, $V v F 3^{\prime} 5^{\prime} H, V v F 3 H 1, V v F 3 H 2, V v D F R$ and $V v A N S$ in the skins and pulp of Yan73 and Cabernet Sauvignon during ripening (Fig. 5). These genes had quite different expression patterns in the different samples. The relative expression amount of all the genes in the pulp of Cabernet Sauvignon was very low, even undetectable, but all these genes were expressed in the pulp of Yan73. The relative expression amount of $V v F 3^{\prime} H$ in the skins of Yan73 berries at harvest was more than that in the Cabernet Sauvignon skins. As for the Yan73 berries, $V v F 3^{\prime} H$ was highly expressed in both the pulp and the skin, while the expression level of $V v F 3^{\prime} 5^{\prime} H$ was very low in the pulp and relatively high in the skin.

OMT catalyses the methoxylation on the position $3^{\prime}$ and $5^{\prime}$ of the B-ring of anthocyanins or flavonols. $V v O M T$ was hardly expressed in the pulp of Cabernet Sauvignon. However, similar trends of this gene expression were seen in both the skin and the pulp of Yan73, and in the skins of Cabernet Sauvignon, in which there was a rapid increase to a maximum at two weeks after véraison, followed by a decline (Fig. 5). The expression levels of both $V v U F G T$ and $V v m y b A 1$ were low in the pulp of the Cabernet Sauvignon berries, but their expression in the red pulp of Yan73 could be as high as that in the skins of Cabernet Sauvignon (Fig. 5).

\section{DISCUSSION}

The accumulation of metabolites showed that whole flavonoid metabolism in the teinturier variety Yan73 was more active than in the non-teinturier variety Cabernet Sauvignon.

Three types of flavonoids were found in both the skins and the pulps of Yan73. Nine gene transcripts involved in the biosynthesis of flavonoids were found in the pulp of Yan73, and their relative expression levels were much higher than those in the pulp of the non-teinturier cultivar, Cabernet Sauvignon. This clearly indicates that the flavonoid pathway exists in Yan73 pulp, as well as in Cabernet Sauvignon pulp. $\mathrm{VvF}^{\prime} \mathrm{H}$ and $\mathrm{VvF}^{\prime} 5^{\prime} \mathrm{H}$ are two key enzymes leading to the synthesis of 3 '-hydroxylated flavonoids and 3',5'-hydroxylated flavonoids respectively (Winkel-Shirley, 2001; Bogs et al., 2006). The expression data of $V v F 3^{\prime} H$ and $V v F 3^{\prime} 5^{\prime} H$ corresponded to a higher percentage of 3 -hydroxylated flavonoids in the pulp of Yan73 relative to that of 3',5'-hydroxylated flavonoids. The assimilated carbon possibly is distributed more to the $\mathrm{F}^{\prime} \mathrm{H}$ branch pathway in the flavonoid metabolism of Yan73 pulp, and mainly to produce 3'-hydroxylated flavan-3-ols and 3'-hydroxylated anthocyanins. This was quite different from the distribution of assimilated carbon in the flavonoid metabolism in Yan73 skin. Meanwhile, a good correlation was seen between the expression level of $V v F 3^{\prime} H$ and the content of 3 '-hydroxylated flavonoids, as well as between the expression level of $V v F 3^{\prime} 5^{\prime} H$ and the content of 3',5'-hydroxylated flavonoids, in the skins of Cabernet Sauvignon and the pulp of Yan73 and Cabernet Sauvignon. In the skins of Yan73, the high expression of $V v F 3^{\prime} H$ could explain the phenomenon of the higher percentage of 3'-hydroxylated flavan-3ols and 3'-hydroxylated anthocyanins in this tissue when compared with those in the skin of Cabernet Sauvignon. Except for $V v F 3^{\prime} H$ and $V v F 3^{\prime} 5^{\prime} H$, other downstream genes, such as $V v F 3 H 1, V v F 3 H 2, V v D F R$ and $V v A N S$, showed a similar abundance of expression in the pulp and skins of Yan73 at harvest (Fig. 5), which was inconsistent with the comparatively higher content of flavonoids in the skins (Fig. 3A). It has been reported that the transcriptional levels of $V v F 3^{\prime} H$ and $V v F 3^{\prime} 5^{\prime} H$ could determine the ratio of 3'-hydroxylated anthocyanins to 3',5'-hydroxylated anthocyanins (Tarara et al., 2008). The present study indicates that the tissue-specific accumulation of flavonoids, not only anthocyanins, is related to the transcriptional expression of $V v F 3^{\prime} H$ and $V v F 3^{\prime} 5^{\prime} H$ in grape berries, even in Cabernet Sauvignon pulp, although the expression of genes was very low and the content of flavan-3-ols was abundant.

Methoxylation on the position $\mathrm{C}^{\prime}$ or $\mathrm{C}^{\prime}$ and $\mathrm{C}^{\prime}$ ' of the anthocyanin B-ring leads to a slight reddening effect on the colouring of anthocyanins (Boss et al., 1996; Gómez-Alonso et al., 2007). Hence, in wine production, the application of Yan73 berries would help wine colour to remain steady, because this teinturier cultivar contains a relatively high concentration of methoxylated anthocyanins. The expression of $V v O M T$ corresponded to the obvious increase in the concentration of methoxylated flavonoids in the early experimental periods (Fig. 4). In addition, $V v U F G T$ is involved in the synthesis of anthocyanins, and $V v m y b A l$ has been demonstrated to specifically regulate the biosynthesis of anthocyanins (Jeong et al., 2006). A close correlation was also observed between the expressions of these two genes and the accumulation of anthocyanins in the skin and pulp of Yan73 and Cabernet Sauvignon respectively. Accordingly, it is suggested that transcriptional regulation of anthocyanin biosynthesis in the pulp may have a similar mechanism to that in the skins. This is in good agreement with recent studies in which anthocyanins were found to accumulate in the pulp and skin of teinturier varieties at the same time (He et al., 2010; Guan et al., 2012). Difference in the percentages of individual anthocyanins were observed between the skin and pulp of Yan73, which has some similarity to previous findings on other teinturier varieties (Obreque-Slier et al., 2010; Lago-Vanzela et al., 2011; Guan et al., 2012). 
Changes in solar radiation and temperature caused by fruit-zone shading could modify the proportion of 3'-hydroxylated and 3',5'-hydroxylated anthocyanins in Vitis vinifera grapes (Downey et al., 2004; Cortell \& Kennedy, 2006; Ristic etal., 2007; Tarara etal., 2008; Chorti etal., 2010).
This might be an integrated result of environmental factors such as temperature, light and rainfall. Environmentallysensitive grape cultivars generally contain a high proportion of 3'-hydroxylated anthocyanins (Chorti et al., 2010). Temperature may have an impact on the gene expression level
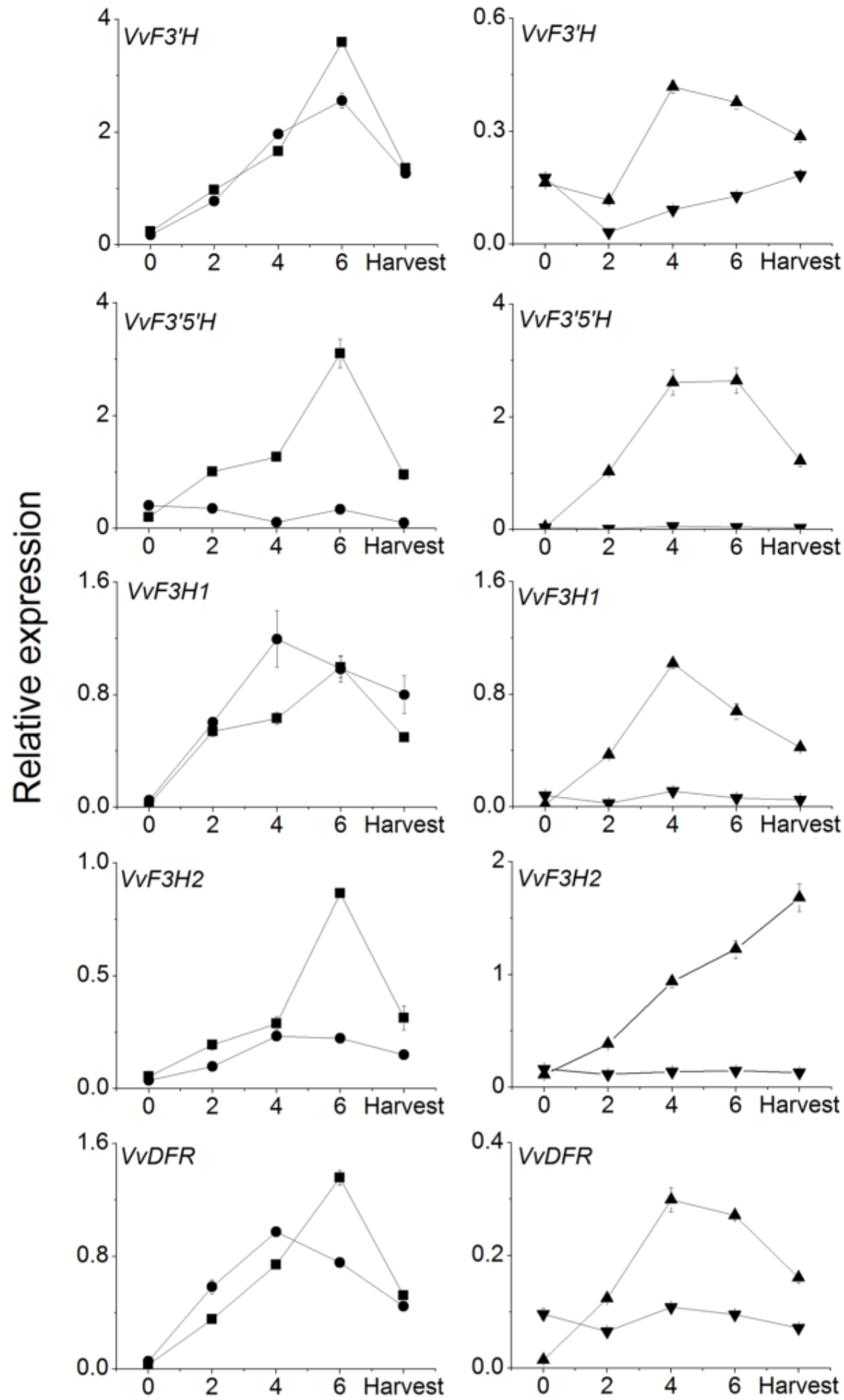

FIGURE 5

Relative expression of $V v F 3^{\prime} H, V v F 3^{\prime} 5^{\prime} H, V v F 3 H 1, V v F 3 H 2, V v D F R, V v A N S, V v U F G T, V v O M T$ and $V v m y b A 1$ in the skin and pulp of Yan73 and Cabernet Sauvignon respectively. YS: the skin of Yan73; YP: the pulp of Yan73; CS: the skin of Cabernet Sauvignon; CP: the pulp of Cabernet Sauvignon. 

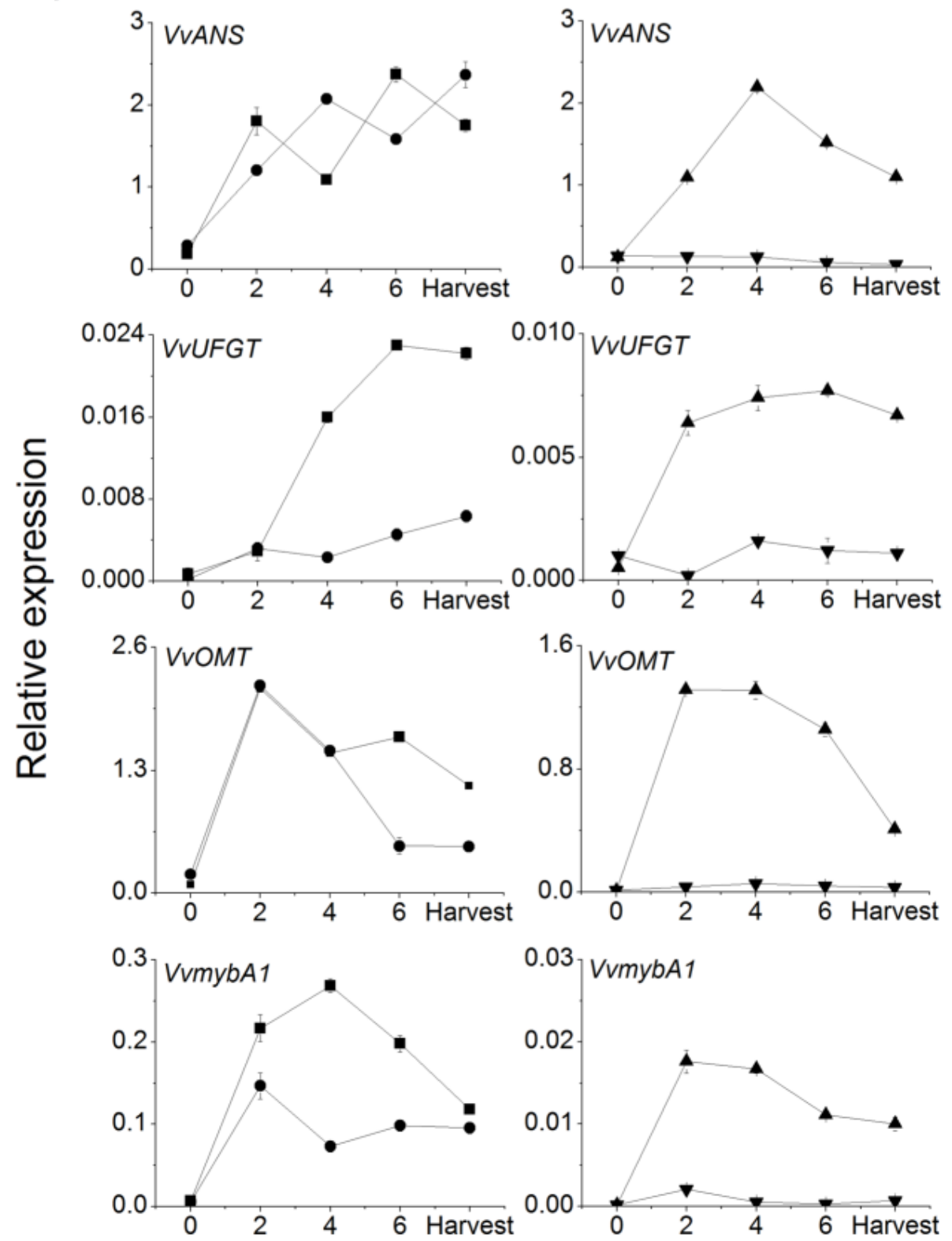

\section{Weeks after véraison}

\section{FIGURE 5 (CONTINUED)}

Relative expression of $V v F 3^{\prime} H, V v F 3^{\prime} 5^{\prime} H, V v F 3 H 1, V v F 3 H 2, V v D F R, V v A N S, V v U F G T, V v O M T$ and $V v m y b A 1$ in the skin and pulp of Yan73 and Cabernet Sauvignon respectively. YS: the skin of Yan73; YP: the pulp of Yan73; CS: the skin of Cabernet

Sauvignon; CP: the pulp of Cabernet Sauvignon.

and enzyme activity in flavonoid biosynthesis, and combined effects of temperature and light are usually observed (Chorti et al., 2010). This also has been demonstrated in the present study. The grape skins, because of exposure to more sunlight and higher temperature, contained more $3^{\prime}, 5^{\prime}$-hydroxylated flavonoids, especially $3^{\prime}, 5^{\prime}$-hydroxylated flavonols and anthocyanins, whereas the Yan73 pulp, which received relatively less sunlight and lower temperature, contained mainly 3 '-hydroxylated flavonoids, especially $3^{\prime}$-hydroxylated flavan-3-ols. This result is in agreement with former studies in which researchers found that less sunlight and lower temperature would result in a substantial decline in the content of flavonoids, especially $3^{\prime}, 5^{\prime}$-hydroxylated flavan-3-ols and 3',5'-hydroxylated anthocyanins (Downey et al., 2004; Cortell \& Kennedy, 2006; Ristic et al., 2007). However, contrasting results have also been reported. Grape shading also has been found to decrease the concentrations of 3 '-hydroxylated anthocyanin and quercetin, and to increase the concentration of 3',5'-hydroxylated anthocyanin (Tarara et al., 2008; Chorti et al., 2010). What factors control the tissue-specific expression of $V v F 3^{\prime} H$ and $V v F 3^{\prime} 5^{\prime} H$ in grape berries - genetic factors or environmental factors? This question needs to be answered.

Our results demonstrate that the different flavonoid profiles in the skins and pulp of Yan73 grape berries are caused mainly by the tissue-specific expression of genes encoding essential enzymes in their biosynthetic pathway, especially for $V v F 3^{\prime} H$ and $V v F 3^{\prime} 5^{\prime} H$. The present study also 
confirmed that the profiles of flavonols, flavan-3-ols and anthocyanins in the pulp of the teinturier variety differed from those in the skin. This will push us to consider a potential impact of the flavonoid components in Yan73 on both colour and mouthfeel when it is utilised in winemaking.

\section{CONCLUSIONS}

Two interesting results were obtained in this study. Firstly, flavonols, flavan-3-ols and anthocyanins were all detected in the pulp of Yan73, and the percentage of 3'-hydroxylated flavonoids was higher than that of $3^{\prime}, 5^{\prime}$-substituted flavonoids in this tissue. This pattern of composition was different from that in the skins of Yan73 and Cabernet Sauvignon, but the same as in the pulp of Cabernet Sauvignon. Secondly, the transcriptional expression of $V v F 3^{\prime} H$ and $V v 3^{\prime} 5^{\prime} H$ was tissue and variety dependent, and their levels of expression showed a high correlation with the accumulation of $3^{\prime}$-hydroxylated and 3',5'-hydroxylated flavonoids.

\section{LITERATURE CITED}

Ageorges, A., Fernandez, L., Vialet, S., Merdinoglu, D., Terrier, N. \& Romieu, C., 2006. Four specific isogenes of the anthocyanin metabolic pathway are systematically co-expressed with the red colour of grape berries. Plant Sci. 170, 372-383.

Balík, J. \& Kumšta, M., 2008. Evaluation of colour content in grapes originating from South Moravia. Czech J. Food Sci. 26, S18-S24.

Bogs, J., Downey, M.O., Harvey, J.S., Ashton, A.R., Tanner, G.J. \& Robinson, S.P., 2005. Proanthocyanidin synthesis and expression of genes encoding leucoanthocyanidin reductase and anthocyanidin reductase in developing grape berries and grapevine leaves. Plant Physiol. 139, 652-663.

Bogs, J., Ebadi, A., McDavid, D. \& Robinson, S.P., 2006. Identification of the flavonoid hydroxylases from grapevine and their regulation dining fruit development. Plant Physiol. 140, 279-291.

Boss, P.K., Davies, C. \& Robinson, S.P., 1996. Anthocyanin composition and anthocyanin pathway gene expression in grapevine sports differing in berry skin colour. Aus. J. Grape Wine Res. 2, 163-170.

Boulton, R.B., Singleton, V.L., Bisson, L.F. \& Kunkee, R.E., 1995. Selection of state of ripeness for harvest and harvesting. In: Boulton, R.B. (ed). Principles and practices of winemaking. Chapman \& Hall, International Thomson Publishing, New York. pp. $52-60$.

Castellarin, S.D. \& Di Gaspero, G., 2007. Transcriptional control of anthocyanin biosynthetic genes in extreme phenotypes for berry pigmentation of naturally occurring grapevines. BMC Plant Biol. 7, 46.

Castellarin, S.D., Pfeiffer, A., Sivilotti, P., Degan, M., Peterlunger, E. \& Di Gaspero, G., 2007. Transcriptional regulation of anthocyanin biosynthesis in ripening fruits of grapevine under seasonal water deficit. Plant Cell Environ. 30, 1381-1399.

Castillo-Muñoz, N., Fernández-González, M., Gómez-Alonso, S., GarcíaRomero, E. \& Hermosín-Gutiérrez, I., 2009. Red-color related phenolic composition of garnacha tintorera (Vitis vinifera L.) grapes and red wines. J. Agric. Food Chem. 57, 7883-7891.

Flavonol profiles of Vitis vinifera red grapes and their single-cultivar wines. J. Agric. Food Chem. 55, 992-1002.

Chorti, E., Guidoni, S., Ferrandino, A. \& Novello, V., 2010. Effect of different cluster sunlight exposure levels on ripening and anthocyanin accumulation in Nebbiolo grapes. Am. J. Enol. Vitic. 61, 23-30.
Cook Papini, P., Mazza, G., Gatti, M. \& Bavaresco, L., 2010. Anthocyanin and aroma profiling of the 'Albarossa' grapevine crossbreed (Vitis vinifera L.) and its parent varieties 'Barbera' and 'Nebbiolo di Dronero'. Vitis 49, 121-127.

Cortell, J.M. \& Kennedy, J.A., 2006. Effect of shading on accumulation of flavonoid compounds in (Vitis vinifera L.) Pinot Noir fruit and extraction in a model system. J. Agric. Food Chem. 54, 8510-8520.

De Villiers, A., Vanhoenacker, G., Majek, P. \& Sandra, P., 2004. Determination of anthocyanins in wine by direct injection liquid chromatography-diode array detection-mass spectrometry and classification of wines using discriminant analysis. J. Chromatogr. A 1054, 195-204.

Downey, M.O. \& Rochfort, S., 2008. Simultaneous separation by reversedphase high-performance liquid chromatography and mass spectral identification of anthocyanins and flavonols in Shiraz grape skin. J. Chromatogr. A 1201, 43-47.

Downey, M.O., Harvey, J.S. \& Robinson, S.P., 2004. The effect of bunch shading on berry development and flavonoid accumulation in Shiraz grapes. Aus. J. Grape Wine Res. 10, 55-73.

Falginella, L., Di Gaspero, G. \& Castellarin, S.D., 2012. Expression of flavonoid genes in the red grape berry of 'Alicante Bouschet' varies with the histological distribution of anthocyanins and their chemical composition. Planta 236, 1037-1051.

García-Beneytez, E., Cabello, F. \& Revilla, E., 2003. Analysis of grape and wine anthocyanins by HPLC-MS. J. Agric. Food Chem. 51, 5622-5629.

García-Beneytez, E., Revilla, E. \& Cabello, F., 2002. Anthocyanin pattern of several red grape cultivars and wines made from them. Eur. Food Res. Technol. 215, 32-37.

Gómez-Alonso, S., Fernández-González, M., Mena, A., García Romero, E. \& Martínez, J., 2007. Anthocyanin profile of Spanish Vitis vinifera L. red grape varieties in danger of extinction. Aus. J. Grape Wine Res. 13, 150156

Guan, L., Li, J., Fan, P., Chen, S., Fang, J., Li, S. \& Wu, B., 2012 Anthocyanin accumulation in various organs of a teinturier cultivar (Vitis vinifera L.) during the growing season. Am. J. Enol. Vitic. 63, 177-184.

Han, F., Zhang, W., Pan, Q., Zheng, C., Chen, H. \& Duan, C., 2008. Principal component regression analysis of the relation between CIELAB color and monomeric anthocyanins in young Cabernet Sauvignon wines. Molecules 13, 2859-2870.

He, F., Fang, X., Hu, M., Pan, Q., Shi, Y. \& Duan, C., 2009. Preparation and biological application of antibodies against leucoanthocyanidin reductase and anthocyanidin reductase from grape berry. Vitis 48, 69-75.

He, J., Liu, Y., Pan, Q., Cui, X. \& Duan, C., 2010. Different anthocyanin profiles of the skin and the pulp of Yan73 (Muscat Hamburg $\times$ Alicante Bouschet) grape berries. Molecules 15, 1141-1153.

Jeong, S.T., Goto-Yamamoto, N., Hashizume, K., Kobayashi, S. \& Esaka, M., 2006. Expression of $V v m y b A 1$ gene and anthocyanin accumulation in various grape organs. Am. J. Enol. Vitic. 57, 507-510.

Jeong, S.T., Goto-Yamamoto, N., Kobayashi, S. \& Esaka, M., 2004. Effects of plant hormones and shading on the accumulation of anthocyanins and the expression of anthocyanin biosynthetic genes in grape berry skins. Plant Sci. $167,247-252$

Jin, Z., Bi, H., Liang, N. \& Duan, C., 2010. An extraction method for obtaining the maximum non-anthocyanin phenolics from grape berry skins. Anal. Lett. 43, 776-785.

Kobayashi, S., Ishimaru, M., Hiraoka, K. \& Honda, C., 2002. Mybrelated genes of the Kyoho grape (Vitis labruscana) regulate anthocyanin biosynthesis. Planta 215, 924-933. 
Kong, Q., Zhu, L., Li, S., Yang, C., Wu, D., Xiu, D. \& Cao, W., 2004. Germplasma resource and breeding of Chinese grapes. In: Kong, Q. (ed). Flora of Chinese grapes. China Agriculture and Technology Press, Beijing. pp. $85-86$.

Lago-Vanzela, E.S., Da-Silva, R., Gomes, E., García-Romero, E. \& Hermosín-Gutiérrez, I., 2011. Phenolic composition of the Brazilian seedless table grape varieties BRS Clara and BRS Morena. J. Agric. Food Chem. 59, 8314-8323.

Liang, N., He, F., Pan, Q., Wang, J., Reeves, M.J. \& Duan, C., 2012. Optimization of sample preparation and phloroglucinol analysis of Marselan grape skin proanthocyanidins using HPLC-DAD-ESI-MS/MS. S. Afr. J. Enol. Vitic. 33, 122-131.

Mattivi, F., Guzzon, R., Vrhovsek, U., Stefanini, M. \& Velasco, R., 2006. Metabolite profiling of grape: Flavonols and anthocyanins. J. Agric. Food Chem. 54, 7692-7702.

Matus, J.T., Loyola, R., Vega, A., Peña-Neira, A., Bordeu, E., Arce-Johnson, P. \& Alcalde, J.A., 2009. Post-veraison sunlight exposure induces MYBmediated transcriptional regulation of anthocyanin and flavonol synthesis in berry skins of Vitis vinifera. J. Exp. Bot. 60, 853-867.

Núñez, V., Monagas, M., Gomez-Cordovés, M.C. \& Bartolomé, B., 2004. Vitis vinifera L. cv. Graciano grapes characterized by its anthocyanin profile. Postharvest Biol. Tech. 31, 69-79.
Obreque-Slier, E., Peña-Neira, A., López-Solís, R., Zamora-Marín, F., Ricardo-da Silva, J.M. \& Laureano, O., 2010. Comparative study of the phenolic composition of seeds and skins from Carménère and Cabernet Sauvignon grape varieties (Vitis vinifera L.) during ripening. J. Agric. Food Chem. 58, 3591-3599.

Ristic, R., Downey, M.O., Iland, P.G., Bindon, K., Francis, I.L., Herderich, M. \& Robinson, S.P., 2007. Exclusion of sunlight from Shiraz grapes alters wine colour, tannin and sensory properties. Aus. J. Grape Wine Res. 13, 53-65.

Tarara, J.M., Lee, J., Spayd, S.E. \& Scagel, C.F., 2008. Berry temperature and solar radiation alter acylation, proportion, and concentration of anthocyanin in Merlot grapes. Am. J. Enol. Vitic. 59, 235-247.

Wang, H., Edward, J. \& Shrikhande, A.J., 2003. Characterization of anthocyanins in grape juices by ion trap liquid chromatography-mass spectrometry. J. Agric. Food Chem. 51, 1839-1844.

Winkel-Shirley, B., 2001. Flavonoid biosynthesis. A colorful model for genetics, biochemistry, cell biology, and biotechnology. Plant Physiol. 126, 485-493.

Xi, Z., Meng, J., Huo, S., Luan, L., Ma, L. \& Zhang, Z., 2013. Exogenously applied abscisic acid to Yan73 ( $V$. vinifera) grapes enhances phenolic content and antioxidant capacity of its wine. Int. J. Food Sci. Nutr. 64, 444-451. 